Recibido: 08/08/15

Aceptado: 14/10/15

Aragón en la Edad Media

26 (2015) 107-140

e-ISSN: 2387-1377

ISSN: 0213-2486

\title{
ESTEBAN SARASA SÁNCHEZ, TODA UNA VIDA DEDICADA A ESTUDIAR Y DIFUNDIR LA HISTORIA MEDIEVAL
}

\author{
ESTEBAN SARASA, A LIFETIME DEDICATED \\ TO STUDY AND TRANSMIT MEDIEVAL HISTORY
}

Ana Isabel Lapeña Paúl

Universidad de Zaragoza

\begin{abstract}
Resumen: Recorrido vital, docente, académico e investigador del medievalista Esteban Sarasa Sánchez, complementado con la pormenorización de su aportación historiográfica al conocimiento del pasado de Aragón en diversos temas: Fernando I, el Compromiso de Caspe, luchas sociales, mudéjares... Asimismo se recogen los servicios prestados a la sociedad aragonesa en general, y a la comunidad universitaria en particular, junto con la labor desempeñada en la gestión de numerosos congresos, jornadas de estudio, etc. desde los puestos que ha desempeñado, tales como, entre otros, de Director de la Sección de Historia y Ciencias Historiográficas o Director de la Cátedra de Historia Jerónimo Zurita, de la Institución Fernando el Católico. Desde esta institución se han emprendido algunos de los más destacados hitos en las últimas décadas en la profundización de los estudios de historia aragonesa y su divulgación.
\end{abstract}

Palabras clave: Esteban Sarasa, historiografía medieval aragonesa, Institución Fernando el Católico of Zaragoza.

\begin{abstract}
Educational, academic and researcher biography of Esteban Sarasa Sánchez, medievalist, explaining his contribution to historiographical knowledge of the past of Aragon in various themes: Ferdinand I, the Compromise of Caspe, Social History, Moorish. Also we have commented other activities of professor Sarasa in favour of the Aragonese society in general or for the university community in particular, at the same time he managed numerous conferences, seminars, etc. from the positions he has held, such as, Head of the Section of History and Historiographic Sciences and Director of the Chair of History Jerónimo Zurita, inside of the Institución Fernando el Católico of Zaragoza. This Institution has made some of the most important events in recent decades about Aragonese History.
\end{abstract}

Keywords: Esteban Sarasa, Aragonese Medieval Historiography, Institución Fernando el Católico de Zaragoza. 


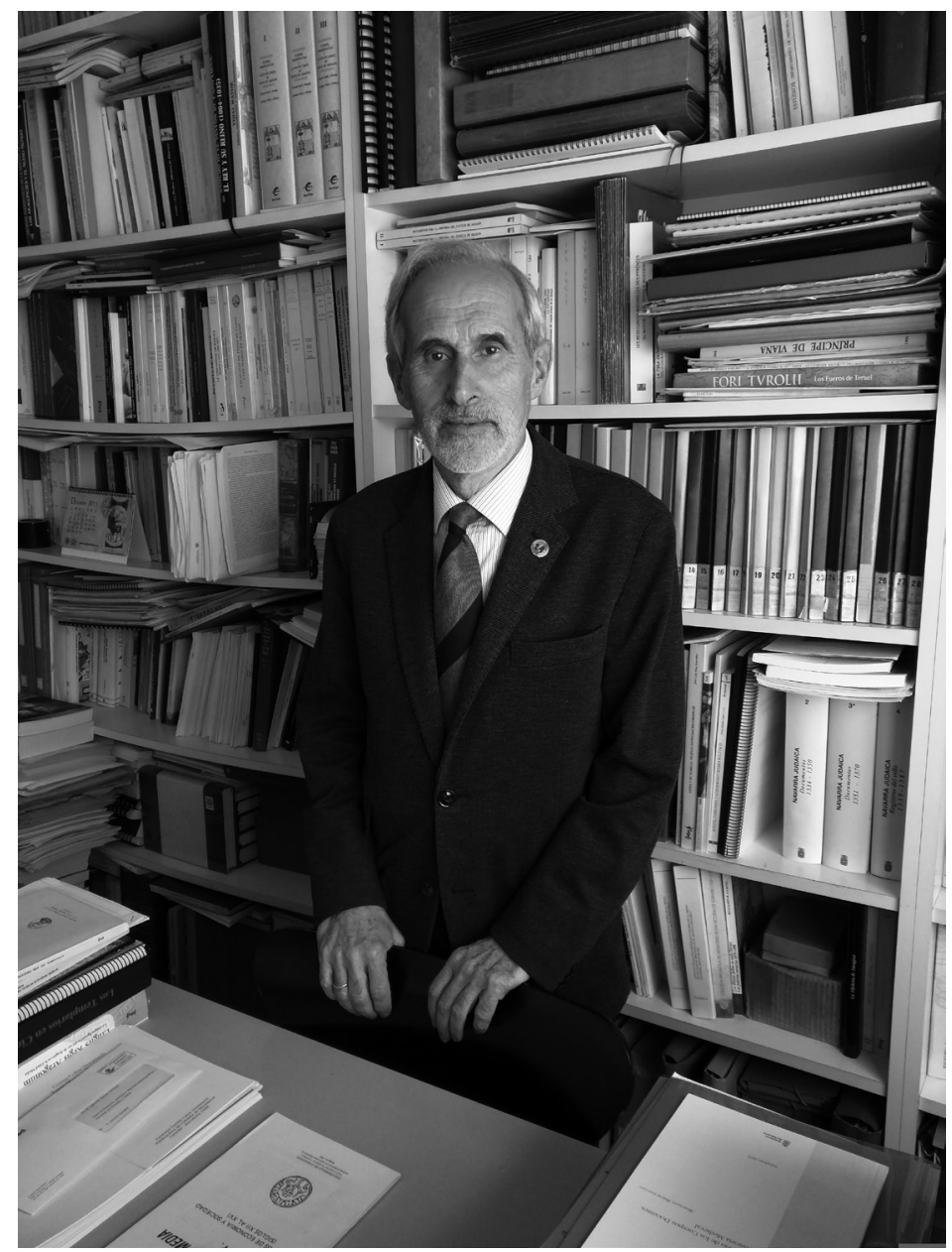

Esteban Sarasa en su despacho de la Facultad de Filosofía y Letras de Zaragoza. Fotografía: Germán Navarro Espinach. 
Debo iniciar estas líneas con la expresión por anticipado de mi afecto hacia la figura del medievalista Esteban Sarasa Sánchez, como profesional del estudio de la Historia y, lo que es más importante, como persona.

Y quiero empezar con el recuerdo de mis primeros contactos con el Dr. Sarasa. Realizaba la carrera de Filosofía y Letras, en la especialidad de Historia, cuando en los clases de don José M. ${ }^{a}$ Lacarra, y más concretamente en la asignatura de «Instituciones Medievales», debíamos acometer un trabajo sobre algún tema concreto que sometíamos a su aprobación. Se trataba de empezar a familiarizarnos con los documentos medievales, manejar los diferentes sistemas de datación cronológica del Medievo, comenzar a extraer los datos que nos habían dejado negro sobre blanco aquellas manos que los habían escrito siglos atrás, familiarizarnos con el periodo y el tema elegido a través de lecturas. Después, dicho trabajo era expuesto en público ante los compañeros y sometido a crítica por don José M. ${ }^{a}$ que nos informaba de los fallos, y también de los aciertos, que habíamos tenido.

A partir de entonces empecé a frecuentar el Departamento de Historia Medieval donde trabajaban una generación de jóvenes y brillantes profesores (J.Á. Sesma Muñoz, la malograda Carmen Orcástegui, Sebastián Andrés Valero, Isabel Falcón Pérez... y el propio Esteban Sarasa) en total sintonía con el citado profesor Lacarra y la entrañable figura de M. ${ }^{a}$ Luisa Ledesma Rubio. En este ambiente comenzaba a consolidarse una destacada generación de medievalistas aragoneses que, con honestidad y total rigor metodológico, empezaron a realizar estudios y monografías de la Baja Edad Media, periodo que hasta entonces había tenido menor presencia en la trayectoria seguida hasta entonces en el citado departamento.

Prácticamente ni mis compañeros ni yo misma teníamos experiencia sobre lo que era el inicio de una pequeña investigación, para mí la primera, y de manejar una bibliografía especializada. Todo eran dudas, pero allí estuvieron siempre Carmen Orcástegui y Esteban Sarasa para ayudarme, dirigiendo mis lecturas, atentos los dos a mis lógicos titubeos iniciales. Y eso no puedo, ni debo, olvidarlo.

Nunca hubiera imaginado que después de tantos años, y más estando al margen de la Universidad en el terreno laboral como es mi caso, haya recibido el encargo de redactar el recorrido profesional como docente e investigador, aspectos indisolubles en el mundo universitario, de alguien que no sólo ha vivido la historia con emoción y profesionalidad, sino que siempre ha facilita- 
do, en todo lo posible, el despegue de nuevas generaciones de historiadores tanto con su incondicional apoyo como en los congresos, jornadas, cursos, etc. que ha promovido, compaginándolo con la enorme preocupación por la difusión de los resultados que se exponían en dichas reuniones, buscando los apoyos económicos necesarios, no siempre fáciles de obtener, para poder editar los frutos conseguidos.

No es una tarea fácil la de trazar en unas pocas páginas toda una vida. Produce un cierto desasosiego el hacerlo porque siempre queda la duda de si mi percepción personal del protagonista y su obra es ajustada, de si he sabido evaluar de manera ponderada la trayectoria del profesor, del investigador, del promotor de acertadas iniciativas para conocer mejor el pasado histórico en los largos siglos del Medievo, especialmente en las tierras de Aragón, cuya capital lo vio nacer en 1946.

Vencido el temor inicial de no estar a la altura de las circunstancias, me pongo a la tarea sin superar del todo el vértigo de pensar que quizás no sepa valorar de manera suficiente aquel trabajo que para su autor fue trascendental por las circunstancias en que se desarrolló y las dificultades que entrañó cualquier artículo, por breve que sea, sobre un aspecto concreto que fue pionero o que abrió nuevos enfoques en las investigaciones, pero también produce miedo la posibilidad de caer en el extremo contrario e incurrir en una visión que pueda ser calificada como hagiográfica, movida por la amistad y el afecto que he comentado en mis palabras iniciales.

En el caso de Esteban Sarasa no hubo una vocación temprana de ser analista del pasado porque, antes de sumergirse definitivamente en el apasionante mundo de la Historia, Esteban Sarasa estudió una Ingeniería Técnica Industrial, de Química por más señas, una carrera de las que entonces se llamaban de «Ciencias». Pero al finalizarla dio un giro inesperado en su vida académica para cursar la licenciatura de Filosofía y Letras (Sección Historia) que culminó en 1974. No era éste un cambio habitual en aquella sociedad. Se trataba de una variación brusca de objetivos profesionales y de emprender una nueva trayectoria, de correr un cierto riesgo, de salvar aquellos obstáculos que inevitablemente tuvieron que surgir para suplir las lagunas que hubiera tras haber estudiado aquel bachiller de compartimentos estancos que se cursaba.

Y tras terminar la licenciatura comenzó su trayectoria investigadora con la Memoria correspondiente. La realizó bajo la dirección del Dr. don José María Lacarra y de Miguel, catedrático de Historia Medieval de la Universidad de 
Zaragoza, y una de las figuras más insignes en el panorama del Medievalismo español desde hacía décadas, cuya autoridad científica ha sido siempre indiscutible y un referente entre los medievalistas. Su rigor se basaba en los documentos como fuente básica. Fruto de aquella investigación que se materializó en 1975 fue el trabajo titulado Las Cortes de Aragón de 1412: Estudio y transcripción de las Actas y Proceso conservado en el Archivo de la Diputación Provincial de Zaragoza, y obtuvo con todo merecimiento la calificación de Sobresaliente «cum laude». Era la primera vez que el profesor Sarasa se imbricaba en un tema que para él ha sido recurrente en su trayectoria: el parlamentarismo medieval aragonés.

Poco después junto con José Ángel Sesma Muñoz publicó un nuevo trabajo (Sesma y Sarasa 1976a). Lo hacían en la editorial Anubar, y no era casual ni mucho menos ya que esta empresa creada en 1960 en Valencia por otro destacado historiador - Antonio Ubieto Arteta - y que en 1977 se trasladó a Zaragoza, siempre ha prestado su máxima atención a la Edad Media, y dentro de la misma a la edición de fuentes documentales y cronísticas, destacando las referidas a temas aragoneses, como base imprescindible para el necesario avance en el conocimiento medieval. Tal y como acabo de comentar el mundo parlamentario aragonés en su etapa medieval ha sido una de las constantes en la historiografía del profesor Sarasa, y si estos trabajos fueron el punto de inicio no lo ha abandonado en ningún momento a lo largo de su devenir vital, como puede comprobarse en la relación bibliográfica que acompaña estas páginas. Téngase además en cuenta que las Cortes de Aragón, al igual que la peculiar institución del Justiciazgo, tema al que también ha dedicado muchas horas de estudio, fueron con toda seguridad las dos instituciones más notables del reino de Aragón. A través de sus trabajos se han ido conociendo los orígenes, la evolución, el funcionamiento, las competencias ... y hasta el ceremonial de esta entidad (Sarasa 1979a). Ha abordado el tema desde diferentes perspectivas y sus investigaciones son punto de referencia obligada.

En 1981 Esteban Sarasa publicaba una síntesis sobre el Compromiso de Caspe (Sarasa 1981a), hecho trascendental para la Corona de Aragón y para la historia de España. Este momento histórico ha generado desde fines del siglo XIX un notable repertorio bibliográfico, pero la obra del Dr. Sarasa se convirtió de manera inmediata en una referencia imprescindible de la historiografía en las décadas siguientes. El tema siempre le ha resultado atractivo y con frecuencia ha vuelto al mismo y desde distintos visiones (Sarasa 1983a, 1996g, 2005b, 2008a, 2012a y d, 2013a y b) analizando, además, algunas de sus con- 
secuencias como, por ejemplo, la rebelión del conde de Urgel y la posterior guerra que provocó (Sarasa 2002e).

Pero volvamos de nuevo la vista atrás, a la década de los 70 del siglo XX. Para entonces ya había comenzado su implicación en el Departamento de Historia Medieval de la Facultad de Filosofía y Letras de la Universidad de Zaragoza al que siempre ha estado vinculado. Primero fue Becario de Colaboración en los años 1973-1974, hecho que conllevaba que empezaras a familiarizarte con una biblioteca especializada que, en el caso del Departamento citado, era de alta calidad. Poco después, terminada ya su licenciatura, obtuvo una Beca de Formación de Personal Investigador del Ministerio de Educación y Ciencia (1975-1977). También empezó a curtirse en la docencia universitaria, y desde el curso académico 1976-1977, y hasta 1981, fue Profesor Ayudante de Clases Prácticas de Historia Medieval en las que eran habituales, por ejemplo, los comentarios de textos y mapas históricos. Durante el curso académico 19811982 fue Profesor Agregado Interino de Historia Medieval, y un año después ejercía como Profesor Adjunto Contratado de Historia Medieval. De allí el siguiente paso de su carrera profesional fue obtener la categoría de Profesor Titular de Universidad, puesto que obtuvo a poco de empezar 1984.

Para entonces, y como era preceptivo, ya había alcanzado una nueva meta. Un peldaño importante para cualquier universitario que se decida a subirlo es la realización de su tesis doctoral, que en su caso fue defendida en 1980. Fue dirigida igualmente por don José M. ${ }^{a}$ Lacarra. En esta ocasión el tema fue Aragón en el reinado de Fernando I, 1412-1416, que obtuvo no sólo el reconocimiento del tribunal que la juzgaba al otorgarle la calificación de Sobresaliente «cum laude», sino también el de la Institución Fernando el Católico (C.S.I.C.) al premiarla en el IV Concurso de Tesis Doctorales, y un año más tarde se le otorgaba además el Premio Extraordinario de Doctorado de la Universidad de Zaragoza.

Era, por otra parte, su vinculación a un periodo - el inicio de una nueva dinastía en Aragón y el reinado del primer Trastámara - que, salvo en el aspecto de lo concerniente al Compromiso de Caspe, no había llamado excesivamente el interés de los historiadores aragoneses. Y Esteban se aproximó a Fernando I desde diversas perspectivas y con frecuencia ha vuelto al tema (Sarasa 1977a, 1981f, 1986a y e, 1993a y c, 1994b, 2013c, 2014b)

Ya he mencionado que por aquellos años en el Departamento de Historia Medieval de la Facultad de Filosofía y Letra de Zaragoza empezaban a co- 
brar cada vez más fuerza las investigaciones sobre la llamada Baja Edad Media. Quienes al principio eran promesas se habían convertido en realidades. Eran ya investigadores maduros que disponían de un amplio abanico de fuentes inéditas, en la mayor parte de los casos, hasta el momento que, al trabajarlas, se convertían en diversos estudios y monografías que completaban cada vez más los conocimientos del periodo medieval aragonés. Se abrían nuevas vías, se reflexionaba sobre aspectos inéditos, o casi, hasta entonces. Y aquí debe enmarcarse un original trabajo sobre la sociedad y los luchas sociales en Aragón (Sarasa 1981b) que empezó a llenar la laguna que existía sobre el tema en Aragón, salvo unas mínimas excepciones, en una etapa histórica donde la conflictividad fue característica frecuente en la Península Ibérica, da igual que fuera en el mundo rural como en el urbano. La indiferencia generalizada de la mayor parte de los historiadores hasta la fecha hacia esta cuestión había sido la tónica general, y los escasos estudios hechos con anterioridad trataban siempre de manera muy somera, prácticamente de pasada, las cuestiones relacionadas con este tema en el reino. Fue un trabajo que completaba otras dos aportaciones elaboradas por el autor un año antes (Sarasa 1979b y 1979c). Y de nuevo volvió al tema algo más tarde (Sarasa 1988c).

Muchos profesores universitarios son requeridos por las editoriales para la realización de los llamados manuales ya que consideran su idoneidad por ser destacados especialistas en sus temas respectivos. En este caso el resultado del trabajo realizado por tres señalados medievalistas (Iradiel, Moreta y Sarasa 1989) fue un texto innovador que se circunscribía, y así lo indicaba el titulo, a los reinos hispanocristianos. Claro que existían obras generales sobre la España Medieval en aquellos momentos, pero este manual universitario acabó convirtiéndose en todo un tratado de referencia obligada. Presentaba la novedad de comenzar a principios del siglo VIII, acontecido ya el desembarco islámico, controlada la Península Ibérica prácticamente en su totalidad por los musulmanes, con una rapidez que aún sorprende, y empezando a asentarse una nueva estructura política, religiosa, legal, cultural y lingüística en el suelo hispano, hecho que marcó la gran diferencia entre la historia medieval española y la de otros espacios europeos. Y es que, por otra parte, el desarrollo de los diversos aspectos del Islam en España ya había sido publicado en otro volumen de la misma editorial realizado por Anwar G. Chejne (1980), en unos tiempos en los que se debatía si la historia de al Andalus es la de la España musulmana o más bien una parcela histórica del Islam: la andalusí. 
Presentaba unos límites temporales que en aquellos años eran poco habituales en el estudio de la Edad Media hispana porque no trataba la historia anterior a la entrada musulmana, y sólo se aproximaba a lo que, en ocasiones, se ha llamado la culminación del proyecto Trastámara. Profundizaba además en cuestiones en las que otros especialistas anteriores habían tocado de manera somera, tales como la economía y la sociedad e incluso aspectos religiosos, culturales y artísticos. Toda una novedad en su tiempo. El manual realizado ayudó a formarse a varias generaciones de futuros historiadores, incluso sigue haciéndolo hoy en día puesto que se han hecho nuevas ediciones, renovadas y actualizadas, pero sin variar lo esencial. Resultó ser un libro interesante también incluso para los no especialistas.

Con posterioridad el Dr. Sarasa recibió el encargo de realizar una monografía muy específica sobre las crisis en la baja Edad Media (Sarasa 1991b). Formaba parte de una colección titulada Las claves de la Historia, integrada por veintiséis breves manuales sobre determinados periodos que iban desde la prehistoria hasta el siglo XX. En cada uno de ellos se analizaban los diferentes temas o épocas de manera sintética, pero pluridisciplinar, ya que se recogían aspectos diversos de la época, cuadros sincrónicos y un amplio número de ilustraciones, ampliamente comentadas. El resultado final de cada uno de estos libros era, llamémosle así, muy sugestivo para los estudiantes, y lo digo porque así me lo comentaban mis propios alumnos, porque eran fáciles de leer y de asimilar, mientras huían de los habituales manuales cargados de conocimientos, pero farragosos en su contenido y en su estética, poco atractivos a los ojos de los estudiantes, cada vez más integrados en un mundo donde la imagen se estaba convirtiendo en algo esencial.

Y en relación con Aragón, Esteban formó parte de la dirección, junto con otros doctores que dirigían la Sección de Historia de la Institución Fernando el Católico, de un proyecto muy útil como instrumento auxiliar para quienes están interesados en la historia de esta Comunidad y no sólo en su etapa medieval, sino desde la Prehistoria hasta el siglo XX. Se trataba de un Atlas de historia de Aragón, formado por un centenar de mapas con someros textos explicativos y una bibliografía esencial que no seguían el modelo habitual de este tipo de obras auxiliares, sino que se disponían de manera independiente, en carpetas separadas que permiten combinar y ver encima de una mesa, los de diferentes momentos o temas. Los alumnos y los docentes hemos tenido con esta obra una herramienta didáctica con grandes posibilidades puesto que la consulta de un mapa es uno de los mejores modos, más rápido y más com- 
prensible, para explicar los cambios políticos y militares, e incluso otros fenómenos como los culturales, intelectuales, sociales y económicos. Un buen mapa, bien realizado y explicado, es mucho más efectivo que decenas de páginas de texto y de enumeración de sucesos y de personajes.

Lo referente a las diversas instituciones fundamentales y hechos decisivos de la historia aragonesa siempre han llamado su atención, y prueba de ello son varios trabajos, bien individuales, bien con otros autores. Un hito absolutamente trascendente de la historia aragonesa fue el denominado Privilegio General de Aragón, ya que fue la base del desarrollo constitucional aragonés que, además, abrió la posibilidad de la participación de las fuerzas del reino en el régimen parlamentario pues, como escribió José M. a Lacarra, sirvió como «primer ensayo de fijar legalmente la relación entre el monarca y el país», se convirtió en punto de partida en la consolidación de instituciones básicas del Aragón medieval, y además supuso la confirmación del ordenamiento jurídico del reino (Sarasa 1984c). Otra institución medieval básica fue el Justiciazgo y la relación de Sarasa con este tema viene de antiguo (Bonet, Sarasa y Redondo 1985) y ha sido otra de sus pautas que se han plasmado en varias aportaciones en los Encuentros de Estudios sobre el Justicia de Aragón tanto como ponente como coordinador (Sarasa 2001a, 2004b, 2006d, 2008b, 2009b).

Otra obra es de obligada alusión, en este caso escrita conjuntamente con la doctora Carmen Orcástegui. con quien formaba un perfecto tándem en lo personal y en el hecho de compartir profesión e intereses científicos. La Historia en la Edad Media (Orcástegui y Sarasa 1991), fue una síntesis perfectamente elaborada donde ambos procedieron a reflexionar en la primera parte del libro sobre el concepto y evolución de la Historia (los géneros, la metodología, el uso de las fuentes...) y en la segunda realizaron un extenso trabajo sobre los historiadores occidentales que elaboraron su obra entre los siglos V al XIII. Intentaron, y lo consiguieron, que esta novedosa visión historiográfica se convirtiera en una herramienta de trabajo para los especialistas de esta disciplina, pero también para los medievalistas en general. Con esta obra sus autores lograron reconstruir uno de los campos más sobresalientes de la cultura medieval. Y por otra parte el tema de la historiografía en diversos momentos, cuestiones y personalidades medievales ha sido siempre objeto del interés del Dr. Sarasa.

En otro orden de cosas no fue éste el primer trabajo conjunto de Carmen Orcástegui y Esteban Sarasa, ni tampoco el último, y de entre todos ellos deben citarse sobre todo los realizados sobre la figura del rey Sancho el Mayor de Na- 
varra (Orcástegui y Sarasa 1990), siendo además un nuevo trabajo sobre el citado monarca la obra póstuma de la recordada Carmen (Orcástegui y Sarasa 2000). La figura de este monarca pamplonés había que reajustarla, por así decirlo, pues aunque se habían realizado estudios, éstos habían ofrecido una visión algo distorsionada y, llamémosla así, excesivamente castellana, caso del estudio de fray Justo Pérez de Urbel en el ya lejano 1950, y la fecha de edición no debe dejar de tenerse en cuenta dada la España que se vivía entonces (Sarasa 2007c). Era necesario «reposicionar», permítaseme la expresión, al biografiado en su justo término y los trabajos citados contribuyeron a ello.

El espíritu inquieto del protagonista de estas páginas le llevaron, junto al Dr. Eliseo Serrano, a promover entre los años 1992 y 2000 unos encuentros que tuvieron una amplia acogida entre los estudiantes. Bajo el genérico titulo de Curso de Historia Medieval y Moderna Ciudad de Sabiñánigo: Espacios Pirenaicos, y bajo el patrocinio del Ayuntamiento de Sabiñánigo e Ibercaja se reunían especialistas de estas dos épocas históricas provenientes de diversas universidades que, además del interés intrínseco que tenían, suponían unos días de intensa convivencia entre profesores y alumnos. Cualquier participante en aquellos encuentros recordará con agrado las preguntas y respuestas que se producían después de cada una de las intervenciones, los debates que surgían y que incluso proseguían fuera del marco que albergaba las sesiones puesto que se compartían mesa, mantel y veladas entre los profesores ya consagrados y quienes estaban terminando de formarse.

En las décadas de los 70 y 80, y en algún caso algo antes, se realizaron en España diversas obras de conjunto sobre las diferentes comunidades autónomas - Gran Enciclopedia Catalana (iniciada en 1969), Gallega (1974), de Andalucía (1979)... por sólo citar unos cuantos casos - , todo ello produjo un auténtica explosión y esfuerzo editorial en una España que se acomodaba a la nueva estructura estatal de las Autonomías y, donde cada territorio buscaba afirmar su identidad. Contenían entradas geográficas, culturales, biográficas, artísticas, etc. y por supuesto históricas, con un amplio elenco interdisciplinar de colaboradores. En este contexto surgió la Gran enciclopedia aragonesa, dirigida por Eloy Fernández Clemente, con una docena de volúmenes aparecidos entre 1980 y 1982 y sucesivos apéndices, donde la colaboración de Sarasa fue habitual en un buen número de voces o entradas, al igual que debe citarse su participación en otras obras de este género como la Enciclopedia de Historia de España dirigida por Artola y la coordinación de la Edad Media en la Gran Enciclopedia de España dirigida por Guillermo Fatás. 
Después de la Facultad de Filosofía y Letras donde ha impartido durante tantos años su docencia, hay un espacio en la ciudad de Zaragoza en el que el Dr. Sarasa ha pasado cientos de horas. Allí ha coordinado trabajos, ha diseñado congresos, jornadas, cursos... Se trata de la Institución Fernando el Católico (IFC), la principal editorial científica aragonesa y una de las más importantes de España. Fue promovida por la Diputación Provincial de Zaragoza y está adscrita al Consejo Superior de Investigaciones Científicas (CSIC). La IFC dirige su actuación a la defensa de todo lo que tiene relación con el patrimonio cultural aragonés. Este organismo de la Excma. Diputación Provincial de Zaragoza ha sido, desde su fundación en 1943, un bastión fundamental en el mundo cultural de toda la Comunidad Aragonesa y no sólo de la demarcación provincial. En la IFC, la Institución por excelencia, ha ocupado a lo largo del tiempo relevantes puestos: Director de la Sección de Historia y Ciencias Historiográficas, Director de la Cátedra de Historia Jerónimo Zurita y Consejero de número de la mencionada Institución.

Otras instituciones han querido, por su parte, contar con su asesoramiento, de tal manera que pueden reseñarse varios nombramientos: Coordinador de la Colección de Ediciones Facsimilares de Historia de Las Cortes de Aragón, Asesor histórico del Justicia de Aragón, Miembro del Consejo Asesor de la Comisión de Heráldica y Simbología de la Diputación General de Aragón (Presidencia del Gobierno). Y como no podía ser menos es miembro de la Sociedad Española de Estudios Medievales y también de otras entidades: Asociación de Historia Social de España, International Commission for the History of Representative and Parliamentary Institutions, Comité Científico de los «Simposia Internacionales de Mudejarismo», Instituto de Estudios Turolenses (C.S.I.C.)...

Otra faceta que puede señalarse es la de haber dirigido la Revista de Historia Jerónimo Zurita, de la Institución Fernando el Católico (C.S.I.C.), de la que todavía forma parte de su consejo asesor, lo mismo que presta este mismo servicio en otras: Hispania (del Centro de Estudios Históricos del C.S.I.C., Madrid), Medievalia (de la Universitat Autonoma de Barcelona y el Institut d’Estudis Medievals, Barcelona), Edad Media. Revista de Historia (de la Universidad de Valladolid), además de ser miembro del Comité Científico de otras varias revistas: Anales de la Universidad de Alicante. Historia Medieval (Universidad de Alicante), revista de Historia del Derecho Ius Fugit, (Facultad de Derecho (de la Universidad de Zaragoza e Institución Fernando el Católico) y Acta Mediaevalia (Universidad de Barcelona). 
No queda aquí su experiencia vital porque si el profesor Sarasa obtuvo su formación en la Universidad de Zaragoza, y después ha ejercido en ella su labor docente durante décadas, ha devuelto con creces lo recibido y ha desempeñado importantes puestos de gestión y responsabilidad académica: Vicesecretario de la Facultad de Filosofía y Letras (1983-1984); Vicerrector de Ordenación Académica (1984-1988); Adjunto al Rector para la Reforma y Nuevas Enseñanzas (1988-1989); Adjunto al Rector para las Relaciones Institucionales (1989-1990); Decano de la Facultad de Filosofía y Letras (19931994), siempre dentro de la citada Universidad cesaraugustana, en «su» Universidad, y también fuera de ella aunque en la mayor parte de los casos en cargos con una estrecha vinculación con la principal institución docente aragonesa, como Director General de Enseñanza Superior (Universidad e Investigación) del Gobierno de Aragón (1999-2001), y Presidente del Consejo Asesor de Investigación, Ciencia y Tecnología, también del Gobierno de Aragón y durante el mismo periodo. Son todas estas responsabilidades una notable demostración de su voluntad de servicio a la sociedad.

Los estudios locales asimismo han estado en su punto de mira, y prueba de ello es la presidencia que ostenta desde 2009 de la Confederación Española de Centros de Estudios Locales (CECEL) del CSIC desde la que se impulsa y coordina la actividad científica y cultural de los cincuenta y ocho centros u organismos de investigación local que, bajo diferentes denominaciones, se integran en ella. La historia de localidades como Calatayud y de comarcas como las Cinco Villas o los Monegros le han resultado atractivos como puede comprobarse en el repertorio bibliográfico anexo.

Pocas parcelas históricas han quedado fuera de su interés y ello lo demuestra que haya sido designado miembro del Consejo Asesor de Heráldica y Simbología del Gobierno de Aragón y asesor histórico del Justicia de Aragón. Cortes, el Justicia de Aragón, los mudéjares, la sociedad bajomedieval, la historiografía, el Compromiso de Caspe y otros aspectos relacionados con el rey Fernando I son temas recurrentes en sus investigaciones históricas. Cualquier persona interesada en conocer estos temas tendrá que recurrir a los trabajos del Dr. Sarasa.

Prácticamente nada más terminar su Memoria de Licenciatura comenzaron sus diversos proyectos de investigación, bien como participante, bien como investigador principal. El primero fue el titulado Las finanzas del rey y del reino en Aragón y Navarra en la primera mitad del siglo $\mathrm{XV}$, cuyo investiga- 
dor principal era don José M. ${ }^{a}$ Lacarra, su maestro. Se desarrolló entre 1976 y 1979 y formaba parte del programa Economía y sociedad en la España Medieval. C.A.I.C.Y.T. (Comisión Asesora de Investigación Científica y Técnica de Presidencia del Gobierno. Proyecto de investigación n ${ }^{\circ} 1.311$ ).

El siguiente proyecto lo realizó en 1982 y ya fue de ámbito internacional: Relaciones internacionales entre Francia, Navarra y Aragón durante la Edad Media. Archives Nationales de France (Paris). Formaba parte de un plan de investigación conjunta entre las universidades de Pau (Francia) y Zaragoza (España) que promovían la Subdirección General de Cooperación Internacional del Ministerio de Educación y Ciencia y la Secretaría de Cooperación Técnica de la Embajada de Francia en Madrid. Y ya que cito esta primera relación con un centro extranjero, tengo que aludir a otras invitaciones recibidas para actuar como ponente. La primera provino desde la República Argentina en una curso titulado Programa de Investigaciones Medievales, organizado por el Consejo Nacional de Investigaciones Científica y Técnicas de la Presidencia del Gobierno Argentino (1992) y en las XXXIX Jornadas Hispánicas sobre la Corona de Aragón promovidas por la Asociación de Hispanistas del Benelux y la embajada de España en La Haya (1993).

A fines de los años 80 del siglo XX un nuevo objetivo investigador acaparó su atención. Se titulaba El gobierno y la administración territorial en el siglo XIV: estructuras político-administrativas y hacendísticas del reino de Aragón, y en esta ocasión la entidad financiadora fue el Consejo Asesor de Investigación del Gobierno de Aragón (C.O.N.A.I), proyecto que, comenzado en 1989, tuvo continuidad hasta 1991. Y durante el año siguiente su compromiso investigador le llevó a participar en un Programa de Investigaciones Medievales que sufragó el Consejo Nacional de Investigaciones Científicas y Técnicas, de la Presidencia del Gobierno Argentino. En los dos casos fue su investigador principal.

Pero entre todos sus proyectos hay uno que quiero destacar por su enorme envergadura. Se titulaba Prospección, registro, catalogación, microfilmación y digitalización de los Fondos documentales sobre Aragón del Archivo de la Corona de Aragón en Barcelona. Lo había promovido la Institución Fernando el Católico (C.S.I.C.), a instancia de Esteban Sarasa, y contó con la financiación de Ibercaja. Mediante el subsiguiente convenio con el Ministerio de Educación y Cultura, llevó la coordinación científica durante diez años, de 1996 a 2006, a la par que la dirección del mismo, con un equipo formado por tres investigadores. Constituyó un esfuerzo muy notable que se plasmó en la crea- 
ción de un Centro de Documentación y Bibliotecas de Ibercaja, instalado en el Palacio de Larrinaga de Zaragoza que puso a disposición del mundo académico o simplemente de quien estuviera interesado en acontecimientos o documentos relacionados con el Reino de Aragón. Todo ello facilitó enormemente la consulta de fondos archivísticos tanto del Archivo de la Corona de Aragón como del Archivo Histórico Nacional porque se digitalizaron cientos de miles documentos (pergaminos, bulas pontificias, registros de cancillería, cartas reales...), con su correspondiente ficha descriptiva, evitando así desplazamientos a Barcelona o Madrid para consultar estos documentos.

El último de sus proyectos hasta la fecha ha sido realizado en los años 20122013. Bajo el epígrafe Antecedentes históricos de la Cámara de Cuentas de Aragón: Edad Media, y como resultado de un contrato de Investigación y Desarrollo entre la Universidad de Zaragoza (Oficina de Transferencia de Resultados de la Investigación, OTRI) y la Cámara de Cuentas de Aragón, acaba de dar sus frutos con una nueva obra - El Maestre Racional y otros antecedentes históricos - elaborado por Guillermo Fatás en la que Esteban Sarasa y Guillermo Redondo han aportado sus conocimientos y los textos para la elaboración final de la historia de este órgano de fiscalización de las cuentas, que se remonta al siglo XIII, en la figura del Maestre Racional, una institución importada desde Sicilia por Pedro III en 1283, y afianzada por Jaime II unos años después, que llevaba «cuenta y razón» de las finanzas del rey, del reino y de la Corona. A dicho Maestre Racional le correspondía la administración del patrimonio real y actuaba como interventor general en cuestiones de ingresos y gastos. De esta manera le fueron asignadas funciones de previsión, dirección y control último de la administración financiera real, destacando, entre todas ellas, la de fiscalización de la gestión financiera. A este cargo le correspondía el control contable de las cuentas de todos los funcionarios que manejaran cantidades de la Hacienda regia. Extrañamente, este interesante organismo apenas había sido objeto de estudio, (Masiá 1950; Lalinde 1976), a pesar de haber tenido un amplio recorrido temporal hasta su extinción a principios del siglo XVIII.

Ha quedado claro en los párrafos anteriores que al profesor Sarasa le ha gustado siempre la divulgación, que el saber no se quede oculto en eruditos libros de estudios, que aunque sean obras excelentes, no llegan al gran público en la mayor parte de los casos, y ha promovido de manera incansable el acercamiento de la historia a personas que están fuera de las aulas universitarias. Bajo su coordinación científica se llevó a cabo entre los años 1997 y 1999 una Historia de Zaragoza que editó conjuntamente el Ayuntamiento de Zaragoza y 
la Caja de Ahorros de la Inmaculada. La formaban trece volúmenes que fueron encargados a diferentes especialistas de cada una de las etapas, desde aquella vieja Salduie ibérica hasta los albores del siglo XXI, cubriendo así toda la trayectoria seguida por una ciudad que tiene bastante más de dos mil años de historia. La colección, de pequeño formato y precio asequible, estaba dirigida a todo tipo de lectores y logró tener una difusión masiva y cubrió el gran hueco dejado por una obra anterior, del año 1976, notable pero incompleta ya que no superaba el período de la Historia Moderna de la ciudad.

En 1997 las Cortes de Aragón decidieron promover la creación de un fondo histórico con el objetivo de adquirir piezas bibliográficas y documentales del patrimonio aragonés que circulaban en el mercado. Contó para ello, sobre todo, con la ayuda financiera de Ibercaja, entidad que lo hizo posible. La directriz inicial era recuperar para Aragón y los aragoneses cualquier texto que pudiera conseguirse, sobre todo en torno a tres temas principales: Aljafería (estudios, literatura, cartografía ...), las Cortes y otras instituciones aragonesas, y una tercera dedicada a la Historia de esta comunidad. Todo ello se hacía bajo la supervisión de Esteban Sarasa y Guillermo Redondo. como asesores en esta cuestión de la institución. Un año después la idea se materializó en la primera exposición y su correspondiente catálogo (Redondo y Sarasa 1998) y se ha seguido realizando de manera periódica (Redondo y Sarasa 2000, 2003, 2005, 2009). Hoy en día puede decirse que el conjunto formado por manuscritos, materiales gráficos, cartográficos y textos impresos es ya de un elevado nivel, tanto por su cantidad como por su calidad, ofreciendo una notable herramienta para los investigadores y personas interesadas.

A lo largo de todos estos años, y en el mismo objetivo de difundir lo más posible la historia al gran público, Sarasa ha ejercido el comisariado de diferentes exposiciones, en diversas ocasiones, mientras que en otros se le ha solicitado su asesoramiento y colaboración en los respectivos catálogos. En el primero de los casos deben reseñarse los siguientes hitos: Aragón. Historia y Cortes de un reino, organizada por las Cortes de Aragón y el Ayuntamiento de Zaragoza en 1991. De esta muestra fue comisario de la selección de piezas documentales y colaborador en su catálogo. En los años 2005-2006 la entidad de ahorro Ibercaja financió y organizó una muestra itinerante que alcanzó ciudades como Palencia, León, Burgos y Córdoba, para finalizar en Sevilla, bajo el epígrafe Mudéjar. Arte, sociedad y cultura de la que fue asimismo comisario y a la par coordinador del catálogo. Por otra parte su asesoramiento y colaboraciones en exposiciones como El espejo de nuestra historia. La 
diócesis de Zaragoza a través de los siglos (Zaragoza 1991-1992) Signos (Arte y cultura en el Alto Aragón románico y gótico), en 1993; Alfonso V el Magnánimo. La imagen real (Zaragoza 1996-1997); Hiberus flumen. El río Ebro y la vida en 1999; Idea de Exea. Novecientos años de historia de la villa de Ejea de los Caballeros, en 2005; Teruel, tierras de frontera (Teruel-Albarracín 2006-2007).

La penúltima de las muestras expositivas que ha organizado, en esta ocasión junto a Ricardo Centellas, fue Ferdinandus Rex Hispaniarum: Príncipe del Renacimiento, fruto del esfuerzo conjunto de las Cortes de Aragón y la Diputación Provincial de Zaragoza, Zaragoza 2006-2007. Se trataba de una gran exposición con más de 250 objetos (pinturas, esculturas, códices, cerámicas, espadas, armaduras, libros o mapas) de muy diversa procedencia, algunos de los cuales nunca se habían mostrado en público, al pertenecer a colecciones privadas. La intención de la exhibición era resumir la dimensión humana, histórica y cultural de Fernando II de Aragón, un rey durante largo tiempo minusvalorado y ensombrecido en la mayor parte de la historiografía tradicional por quien fuera su primera esposa, la reina Isabel de Castilla, imagen por otra parte no veraz. Esfuerzos como el que se comenta y nuevos enfoques historiográficos realizados en los últimos tiempos van sacando a la luz la verdadera trascendencia del personaje al que coetáneos de tanta importancia como Maquiavelo elogiaron. Fernando supo dar a su política una dimensión europea y tener una proyección internacional, impregnada de las ideas nuevas del Renacimiento y del Estado Moderno. Y para terminar esta faceta del Dr. Sarasa debe citarse la última exposición que ha organizado hasta la fecha actual. Se tituló Archivo de la Corona de Aragón, promovida por el Ministerio de Cultura (Archivo de la Corona de Aragón), el Gobierno de Aragón y de nuevo Ibercaja, El escenario fue la ciudad de Zaragoza y tuvo lugar entre mayo y julio de 2007. Diversos legajos, más de 60 , se mostraron a quienes se acercaron al palacio Larrinaga.

Otra característica de Esteban Sarasa es su habitual diligencia en la preparación y coordinación, incluso la dirección, de congresos, reuniones científicas, coloquios y cursos de historia. Abruma la relación total de su gestión y aun a riesgo de resultar excesivo, no me resisto a recoger su trayectoria en este campo:

- Los destierros aragoneses: judíos y moriscos, liberales y republicanos (Institución Fernando el Católico. Zaragoza, 1986). 
- I Curso de Historia de Aragón de la Institución Fernando el Católico. Sobre Generalidades (Zaragoza, 1986-1987).

- Los aragoneses y el mediterráneo en la Edad Media. (Institución Fernando el Católico, 1987).

- II Curso de Historia de Aragón de la Institución Fernando el Católico. Sobre Economía (Zaragoza, 1987-1988).

- Cincuenta años de Historiografía de la Corona de Aragón, homenaje a Andrés Giménez Soler (Banco Zaragozano y Universidad de Zaragoza, 1988).

- III Curso de Historia de Aragón de la Institución Fernando el Católico. Sobre Sociedad (Zaragoza, 1988-1989).

- IV Curso de Historia de Aragón de la Institución Fernando el Católico. Sobre Arte (Zaragoza, 1989-1990).

- Las Cortes en la Corona de Aragón (Cortes de Aragón y Universidad de Zaragoza, 1991).

- La Historia en el horizonte del año 2000: compromisos y realidades (Institución Fernando el Católico. Zaragoza, 1995).

- Historiadores de la España Medieval y Moderna (Institución Fernando el Católico. Zaragoza, 1997).

- Fueros y Ordenamientos Jurídicos Locales en la España Medieval (Institución Fernando el Católico y Confederación Española de Estudios locales del CSIC, Zaragoza 2003).

- Señorío y feudalismo: 15 años después (Institución Fernando el Católico. Zaragoza, 2004).

- Las Cinco Villas Aragonesas en la Europa de los siglos XII y XIII. De la frontera natural a las fronteras políticas y socioeconómica: foralidad y municipalidad (Diputación de Zaragoza, Institución Fernando el Católico, Centro de Estudios de las Cinco Villas y Universidad de Zaragoza, Ejea, Sos del rey Católico y Uncastillo, 2005).

- Sexto Encuentro de Estudios sobre El Justicia de Aragón: instrumentos para el conocimiento de sus orígenes y desarrollo de una institución clave en la Edad Media (Justicia de Aragón y Universidad de Zaragoza, Zaragoza, 2005)

- La sociedad en Aragón y Cataluña en el reinado de Jaime I(1213-1276), (Institución Fernando el Católico, Zaragoza 2008). 
- Monarquía, crónicas, archivos y cancillerías en los reinos HispanoCristianos, siglos XIII-XV (Institución Fernando el Católico, Zaragoza 2011).

Con igual buen hacer y efectividad ha coordinado varios congresos y simposia internacionales: La Marca Superior de al-Andalus, siglos VIII-IX. (C.N.R.S. de France, Casa de Velázquez del Gobierno Francés y Universidad de Zaragoza. Huesca, 1988). Feudalismo y señorío en la Península Ibérica, siglos XII-XIX (Institución Fernando el Católico. Zaragoza, 1989); La Corona de Aragón y el Mediterráneo (Institución Fernando el Católico. Zaragoza, 1992). Y en los estudios sobre el mundo de los mudéjares cabe subrayar los Simposia Internacionales de Mudejarismo: IV (1987), V (1990), VI (1993), VII (1996), VIII (1999), IX (2002) y X (2005) celebrados en la ciudad de Teruel, promovidos a partir de 1993 por el Centro de Estudios Mudéjares, organismo que está respaldado por un comité científico de reconocidos investigadores nacionales y extranjeros en muy variadas disciplinas, tales como la Historia, el Arte, el Patrimonio, el Pensamiento, etc.

Incluso ha organizado diversos congresos internacionales en relación a parcelas ajenas a la historia medieval: El Conde de Aranda y su tiempo (Institución Fernando el Católico. Zaragoza, 1998); o Felipe Vy su tiempo (Institución Fernando el Católico. Zaragoza, 2001).

Pero además su saber personal lo ha volcado en la dirección de varias tesis doctorales y proyectos de investigación. Y todas ellas han culminado con la obtención de la máxima calificación otorgada por los tribunales que las juzgaron. Lógicamente el mérito principal es de las propias personas que las realizaron, pero la dirección de las mismas también es un elemento básico y fundamental a destacar. A día de hoy sigue desarrollando esta faceta de orientación y dirección con otros doctorandos.

Son todas ellas facetas que deben subrayarse de manera especial en relación con la sociedad actual donde las humanidades no están de moda ni siquiera en las universidades. Hay quien habla de eclipse de las mismas. No voy a negarlo porque es un hecho y además un signo alarmante pero, tras la ocultación total o parcial, el astro vuelve a brillar. Creo, y sobre todo espero, que la sociedad reaccionará ante el duro panorama que hace poco se vislumbraba y que hoy en día empieza a ser una dura y triste realidad: la incapacidad para comprender lo que lee y la imposibilidad de esbozar unas formas de expresión coherentes son ya un hecho, ya nadie debate de manera inteligente, sólo se dan opiniones a gritos, ya ni siquiera se conversa... Se está asentando de manera definitiva una 
sociedad donde triunfa la insensibilidad humanística y, sobre todo, donde se impone una cada vez mayor tiranía tecnológica, excluyendo palabras con mayúscula tales como Arte, Literatura, Historia... Hagamos que la reversión sea posible. Sólo con esfuerzo, con trayectorias vitales como la mantenida por docentes e investigadores como el profesor Sarasa saldremos de esta encrucijada.

Imposible abordar de manera más detallada todo el esfuerzo del profesor Sarasa a lo largo de su vida, ya que debe tenerse en cuenta que es autor de más de doscientas publicaciones de la especialidad entre artículos, ponencias, comunicaciones y colaboraciones. Como ha podido comprobarse el balance de su recorrido vital en relación a su compromiso docente e investigador es altamente positivo. Cientos de estudiantes han seguido sus explicaciones en las aulas a lo largo de tantos años y seguido sus orientaciones a la hora de formarse como historiadores. Su despacho ha estado abierto siempre a quienes querían acercarse a él. Esteban ha sido y es un buen medievalista y su trayectoria lo demuestra. Por otra parte los centenares de páginas que ha escrito han aproximado la Historia con mayúsculas a una sociedad que, como se ha indicado en párrafos anteriores, es hoy en día poco proclive a este tipo de temas. Por la parte que te toca, gracias Esteban. Con docentes e investigadores como tú las Humanidades no desaparecerán de nuestra civilización.

Finalmente, como colofón, si la trayectoria académica del profesor Sarasa se resume en los ocho tramos (quinquenios) reconocidos de docencia universitaria con evaluación positiva destacada (40 años), y en los cinco tramos (sexenios) de actividad investigadora (30 años), su proyección social se refleja en otras contribuciones: socio-fundador de la Asociación Cultural Los Sitios de Zaragoza y socio de honor de la misma, director del Centro de Estudios Mudéjares de Teruel durante 12 años, miembro de El Rolde de Aragón, miembro de la Fundació Ernest Lluch, evaluador de la Agencia de Gestió d'Ajuts Universitaris i de Recerca de la Generalitat de Catalunya, así como de la Agencia Nacional de Evaluación y Prospección (ANEP) de la Dirección General de Investigación Científica y Técnica del Ministerio de Economía y Competitividad; o, más recientemente, miembro del Comité de Bioética de Aragón en representación de la Universidad de Zaragoza y a propuesta de su Rector. Y dentro de esta proyección social y humana, destaca, de forma especial, su compromiso con la infancia desfavorecida. Compromiso que le ha llevado a implicarse en un altísimo grado con Unicef y sus proyectos: ha presidido UNICEF-Comité Aragón y, como tal, ha sido miembro del Patronato de UNICEF-Comité Español; actualmente es vocal del Comité de Aragón. 


\section{Producción bibliográfica de Esteban Sarasa}

ÁLVARO, M. I., BORRÁS, G. y SARASA, E. (coords.) (2005), Mudéjar, Catálogo de la exposición itinerante, Zaragoza, Ibercaja.

BELTRÁN, M., CORRAL, J. L., SARASA, E. y SERRANO, E. (dirs.) (1992) Atlas de Historia de Aragón, Zaragoza, Institución Fernando el Católico.

BONET, Á., SARASA, E. y REDONDO, G. (1985), El justicia de Aragón: Historia y Derecho. Introducción a la edición facsimilar de la Ilustración a los quatro procesos forales de Aragón y segunda ilustración de J. Fco. La Ripa. Zaragoza, Cortes de Aragón.

FATÁS CABEZA, G. (2015), La Cámara de Cuentas de Aragón: el Maestre Racional y otros antecedentes históricos (sobre textos de Esteban Sarasa Sánchez y Guillermo Redondo Veintemillas), Zaragoza, Cámara de Cuentas de Aragón.

IRADIEL, P., MORETA, S. y SARASA, E. (1989), Historia medieval de la España cristiana, Madrid, Cátedra.

ORCÁSTEGUI, C. y SARASA, E. (1977), «Miguel Palacín, merino de Zaragoza en el siglo XIV», Aragón en la Edad Media, 1, 51-132.

- (1981), «El libro-registro de Miguel Royo, merino de Zaragoza en 1301: Una fuente para el estudio de la Sociedad y Economía Zaragozanas a comienzos del siglo XIV», Aragón en la Edad Media, 4, 87-156.

- (1990), Sancho Garcés III, el Mayor (1004-1035), Pamplona, Mintzoa. (Col. Reyes de Navarra, 6).

- (1991), La Historia en la Edad Media. Historiografía e historiadores en Europa Occidental (siglos V-XIII), Madrid, Cátedra.

- (1993), «El Alto Aragón en la época gótica: siglos XIII-XV», en T. Luesma (coord.), Signos: Arte y cultura en el Alto Aragón medieval, 26 junio-26 septiembre 1993, Zaragoza, Gobierno de Aragón, 147-156.

- (2000), Sancho III el Mayor (1004-1035), Burgos, Olmeda. (Col. Corona de España. Reyes de Navarra, 36).

REDONDO, G. y SARASA, E. (1984), «Edición e introducción histórica», en G. Martel, Forma de celebrar cortes en Aragón, edición facsimilar, Zaragoza, Cortes de Aragón, 5-45.

- y SARASA, E. (1988), «El señorío de Ariza de la familia Palafox y la sentencia de Celada: alteraciones campesinas y triunfo señorial en el tránsito de la Edad Media a la Moderna», Revista de Historia Jerónimo Zurita, 58, 31-50.

- y SARASA, E. (1995), «Introducción», en J. Blancas, Comentarios de las cosas de Aragón, Edición facsimilar de la traducción castellana del original latino de 1878, Zaragoza, Cortes de Aragón, 9-22.

- y SARASA, E. (1998), «Introducción», en Fondo Documental Histórico de las Cortes de Aragón (1996-1998), Zaragoza, Cortes de Aragón, 9-15. 
REDONDO, G. y SARASA, E. (2000), «Introducción», en Fondo Documental Histórico de las Cortes de Aragón (1998-2000), Zaragoza, Cortes de Aragón, 11-18.

- y SARASA, E. (2003), «Introducción», en Fondo Documental Histórico de las Cortes de Aragón (2000-2002), Zaragoza, Cortes de Aragón, 11-18.

- y SARASA, E. (2005a), «Introducción», en Fondo Documental Histórico de las Cortes de Aragón (2002-2004), Zaragoza, Cortes de Aragón, 9-22.

- y SARASA, E. (2005b), «Prólogo» en Colección de Cortes de los antiguos reinos de España. Por la Real Academia de la Historia, edición facsimilar de la de 1855, Zaragoza, Cortes de Aragón, 11-14.

- y SARASA, E. (2009), «Introducción», en Fondo Documental Histórico de las Cortes de Aragón (2005-2007), Zaragoza, Cortes de Aragón, 11-24.

REDONDO, G. y SARASA, E. (coords.) (2001), «Introducción», en Marqués de Pidal, Historia de las alteraciones de Aragón en el reinado de Felipe II, Zaragoza, Justicia de Aragón, edición facsimilar.

SARASA, E. (1977a), «El señorío jurisdiccional de Trasmoz en el siglo XV», Homenaje al profesor Lacarra. Miscelánea de Estudios Medievales, vol. IV, Zaragoza, Anubar, 79-92.

- (1977b), Fernando I y Zaragoza. La coronación de 1414, Zaragoza, Ayuntamiento de Zaragoza. (Col. Cuadernos de Zaragoza, 10).

- (1977c), «La Edad Media», en Los aragoneses, Madrid, Istmo, 93-119.

- (1977d), «Nacimiento y expansión del reino de Aragón» y «La Corona de Aragón», en E. Fernández-Clemente y G. Fatás (coords.), Aragón, nuestra tierra, Zaragoza, Guara, 65-96.

- (1978), «Aragón hasta su fusión con Castilla», en El hecho histórico. I Congreso de Estudios Aragoneses, Zaragoza, Institución Fernando el Católico, 43-63.

- (1979a), Las Cortes de Aragón en la Edad Media. Zaragoza, Guara.

- (1979b), «La condición social de los vasallos de señorío durante el siglo XV: criterios de identidad», Aragón en la Edad Media, 2, 203-244.

- (1979c), «Sociedad y conflictos sociales en Aragón: siglos XIV y XV», en I Jornadas sobre el estado actual de los estudios de Aragón, Zaragoza, Instituto de Ciencias de la Educación de la Universidad de Zaragoza, vol. 1, 302-306.

- (1979d), «Las Cortes de Aragón en la Edad Media», en I Jornadas sobre el estado actual de los estudios sobre Aragón, Zaragoza, Instituto de Ciencias de la Educación de la Universidad de Zaragoza, vol. 2, 635-643.

- (1980a), «Notes sur la condition sociale des vassaux seigneuriaux dans le royaume d'Aragon aux XIV et XV siècles», Le Moyen Âge. Revue d'histoire et de philologie, 86/1, 5-47.

— (1980b), «El bandolerismo medieval en Aragón», Historia 16, 46, 52-57.

- (1980c), «Demografía medieval aragonesa», en II Jornadas sobre el estado actual de los estudios de Aragón, Zaragoza, Instituto de Ciencias de la Educación de la Universidad de Zaragoza, vol. 2, 529-534. 
SARASA, E. (1981a), Aragón y el Compromiso de Caspe, Zaragoza, Librería General.

- (1981b), Sociedad y conflictos sociales en Aragón (siglos XIII-XV): estructuras de poder y conflictos de clase, Madrid, Siglo XXI.

- (1981c), «Durán de Huesca, un heterodoxo aragonés en la Edad Media», en D. Buesa (coord.), Miscelánea de estudios en honor de don Antonio Durán Gudiol, Zaragoza, Guara, 225-238.

- (1981d), «Las Cortes de Aragón», Historia y Vida, 155, 55-67.

- (1981e), «Mitos y ritos feudales en Aragón: el caso de doña Brianda de Luna», en I Congreso de Aragón de Etnología y Antropología (1979, Tarazona), Zaragoza, Institución Fernando el Católico, 127-132.

- (1981f), Aragón en el reinado de Fernando I (1412-1416), Zaragoza, Universidad de Zaragoza, 1981.

- (1982), «La hacienda real de Aragón en el siglo XV», en Historia de la Hacienda Española (épocas antigua y medieval), Homenaje a Luis García de Valdeavellano, Madrid, Instituto de Estudios Fiscales, 823-844.

- (1983a), «El compromiso de Caspe. Revisión de un acontecimiento histórico a fines del siglo XX», Cuadernos de Estudios Caspolinos, 9, 19-28.

- (1983b), «Los precedentes medievales de la Universidad de Zaragoza», en Historia de la Universidad de Zaragoza, Madrid, Editora Nacional, 17-45.

- (1984a), «Rentas, derechos señoriales, producción y precios agrarios en Aragón en el siglo XV», en Congreso de historia rural: siglos XV al XIX, Madrid, Universidad Complutense, 827-834.

- (1984b), «La arqueología industrial: estudio histórico-arqueológico del pasado industrial español», en Actas del II Congreso de la Sociedad Española de Historia de las Ciencias, Zaragoza, Universidad de Zaragoza, vol. III, 327-333.

- (1984c), El Privilegio General de Aragón. La defensa de las libertades aragonesas en la Edad Media, Zaragoza, Cortes de Aragón.

- (1984d), «Visión política del Mediterráneo en la baja Edad Media», Annals de la segona Universitat d'Estiu, Principado de Andorra, Consellería d'Educació i Cultura, 37-48.

- (1984e), «La Edad Media en Aragón», en M. Barceló (dir.), Historia de los pueblos de España. II. Los antiguos territorios de la Corona de Aragón Barcelona, ArgósVergara, 23-40.

- (1985a), «La alimentación de un rey aragonés y su séquito a comienzos del siglo XV», en D. Menjot (ed.), Actes du Colloque de Nice. Tomo II: Cuisine, manières de table, régimes alimentaires, Nice, Centre d'Études Medievales, 223-231.

- (1985b), «Onomástica zaragozana del siglo XIV», en E. Saez, C. Segura y M. Cantera, La ciudad hispánica durante los siglos XIII al XVI, Madrid, Universidad Complutense, vol. II, 1201-1214. 
SARASA, E. (1985c), «Braulio Foz y la Historia de Aragón», Cuadernos de Estudios Borjanos, 15-16, (Homenaje a Braulio Foz), 71-93.

- (1985d), «La construction a Saragosse a la fin du Moyen Age: conditions de travail, materiaux, prix et salaires», en La construction dans la Péninsule Ibérique $\left(X I^{e}-X V I^{e}\right)$, Cahiers de la Mediterranée, 31, Nice, Université de Nice, 73-93.

- (1985e), «Domingo Ram y Lanaja ( $i$-1445)», en G. Fatás (dir.), Aragoneses ilustres. II, Zaragoza, Caja de Ahorros de la Inmaculada, 133-134.

- (1986a), Aragón en el reinado de Fernando I (1412-1416), Gobierno y administración. Constitución política. Hacienda real, Zaragoza, Institución Fernando el Católico.

- (1986b), «El feudalismo en Aragón: una hipótesis de trabajo y comprensión para la época medieval», en Homenaje a José M. ${ }^{a}$ Lacarra, Pamplona, Institución Príncipe de Viana, 669-686. (Col. Príncipe de Viana. Anejos, 3).

- (1986c), «La arqueología industrial: por un nuevo conocimiento histórico», en Estudios en homenaje al Dr. Antonio Beltrán, Zaragoza, Facultad de Filosofía y Letras, 1019-1028.

- (1986d), «Las relaciones Iglesia-Estado en Aragón durante la Baja Edad Media», en J. P. Genêt y B. Vincent (eds.), État et Église dans la génese de l'État Modern (Actes du colloque organisé par le Centre National de la Recherche Scientifique et la Casa de Velázquez). Madrid, Casa de Velázquez, 165-174.

- (1986e), «Los aragoneses y el Cisma de Occidente en el reinado de Fernando I», en Jornades sobre el Cisma d'Occident a Catalunya, les Illes i el Pais Valenciá. Barcelona, Institut Estudis Catalans, 233-240.

- (1986f), «La financiación de las tropas castellanas de Don Enrique de Trastámara en su intervención a favor del rey de Aragón en la guerra de los dos Pedros», en Estudios en homenaje a Don Claudio Sánchez Albornoz en sus 90 años. Buenos Aires, Instituto de España, 529-534. (Col. Cuadernos de Historia de España, Anexos, 4).

- (1986g), «Les Cortes d’Aragón au Moyen-Age: gouvernement et politique. Rapports entre la monarchie et les aragonais», en D. Menjot (dir.), Pouvoirs et sociétés politiques dans les Royaumes Ibériques au Bas Moyen Age (fin XIII sièclemilieu $X V^{e}$ siècle)», Nice, Université de Nice, 141-150.

- (1988a), «La arqueología industrial y la Edad Media: la innovación tecnológica como factor de cambio y reflejo de las mentalidades», en II Jornades sobre la Protecció i Revalorització del Patrimoni Industrial, Barcelona, Generalitat de Catalunya, 21-24.

- (1988b), «Las Cortes de Aragón en la Edad Media», en Las Cortes de Castilla y León en la Edad Media. I Congreso científico sobre historia de las Cortes de Castilla y León (Burgos, 1986), Valladolid, Cortes de Castilla y León, vol. II, 492-542. 
SARASA, E. (1988c), «La sociedad aragonesa en la Baja Edad Media. Conflictividad latente: antagonismos y desequilibrios», en Destierros aragoneses. I: Judios y moriscos, Zaragoza, Institución Fernando el Católico, 9-23.

- (1988d), «Las Cinco Villas en la crisis medieval: notas para su análisis e interpretación, macrohistoria y microhistoria», en II Jornadas de estudio de las Cinco Villas: Historia Medieval, Ejea de los Caballeros, Centro de Estudios de las Cinco Villas, 9-23.

- (1988e), «Durán de Huesca. Precursor heterodoxo de las órdenes mendicantes, en G. Fatás (dir.), Aragón en el mundo, Zaragoza, Caja de Ahorros de la Inmaculada, 122-127.

- (1988f), «Las universidades del reino de Aragón (Huesca y Zaragoza) y de Lérida», en Estudios sobre los orígenes de las universidades Españolas. Homenaje de la Universidad de Valladolid a la Universidad de Bolonia en su IX Centenario, Valladolid, Universidad de Valladolid, 85-95.

- (1989a), «La memoria del agua: la economía hidráulica en el valle medio del Ebro, ¿un ejemplo de supervivencia o de nueva implantación tras la conquista cristiana en el siglo XII?», Aragón en la Edad Media, 8 (Al profesor emérito Antonio Ubieto Arteta en homenaje académico), 633-646.

- (1989b), «El enfrentamiento de Pedro el Ceremonioso con la aristocracia aragonesa: la Guerra con la Unión y sus consecuencias», en Pere el Cerimoniós i la seva época. Barcelona, CSIC-Institució Milà i Fontanals, 35-45.

- (1989c), «Las actas de cortes medievales como fuentes de investigación: aspectos metodológicos», en Metodología de la investigación científica sobre fuentes aragonesas. IV, Zaragoza, Instituto de Ciencias de la Educación de la Universidad de Zaragoza, 322-357.

- (1990a), «Los antecedentes» en J. A. Dueñas (coord.), Historia del periodismo en Aragón, Zaragoza, Diputaciones de Huesca, Teruel y Zaragoza y Asociación de la Prensa de Zaragoza, 19-20.

- (1990b), «Concejos y ciudades medievales en el reino de Aragón. Hacia una tipología socioeconómica de los municipios aragoneses en la Edad Media: de la foralidad a la municipalidad», en Concejos y ciudades en la Edad Media. II Congreso de Estudios Medievales, León, Fundación Sánchez Albornoz, 73-122.

- (1990c), «Cincuenta años de historia medieval de Aragón (1940-1989», Hispania vol. 50/2, 175, (Ejemplar dedicado a: 50 años de historiografía española y americanista), 701-717.

- (1991a), Aragón. Historia y cortes de un reino, Zaragoza, Cortes de Aragón y Ayuntamiento de Zaragoza.

- (1991b), Las claves de las crisis en la baja Edad Media. 1300-1450, Barcelona, Planeta. 
SARASA, E. (1991c), «Aragón en torno al año mil: estructura social, comportamientos económicos y respuesta cultura», en X. Barral (dir.), Catalunya i França meridional a l'entorn de l'any mil. Barcelona, Generalitat de Catalunya, 140-149.

- (1991d), «Las cortes de Aragón en la Edad Media: estado de la cuestión y planteamiento general», en Les Corts a Catalunya. Actes del Congrès d'Historia Institucional, Barcelona, Generalitat de Catalunya, 296-303.

- (1991e), «Introducción», en Braulio Foz, Memoria sobre el Parlamento de Caspe (edición facsimilar de la de 1848), Zaragoza, Institución Fernando el Católico.

- (1992), «El Reino de Aragón en la Baja Edad Media (siglos XIV y XV): límites territoriales, divisiones administrativas, jerarquía y sistema urbano» $\mathrm{y}$ «Señorío y realengo: mapa de jurisdicciones sobre el territorio aragonés a comienzos del siglo XV», en M. Beltrán y otros (dirs.), Atlas de historia de Aragón, Zaragoza, Institución Fernando el Católico, mapas 51 y 55.

- (1993a), «Poliorcética, economía de guerra y hacienda en el siglo XV (El asalto a Balaguer por Fernando I en 1413)», en La organización militar en los siglos XV y XVI. Actas de las II Jornadas Nacionales de Historia Militar, Sevilla, Capitanía General de la Región Sur, 369-376.

- (1993b), «Concejos y ciudades del Camino de Santiago en Aragón y Navarra: del crecimiento a la crisis», en C. Cid Priego (coord.), Las artes en los caminos de Santiago, 233-350.

- (1993c), «Fernando I», en R. Centellas (coord.), Los reyes de Aragón, Zaragoza, Caja de Ahorros de la Inmaculada, 143-148.

- (1994a), «Sancho Ramírez, rey de Aragón y de Navarra», en E. Sarasa (coord.), Sancho Ramírez, rey de Aragón y su tiempo (1064-1094), Huesca, Instituto de Estudios Altoaragoneses, 11-24.

- (1994b), «La mesa viajera del rey de Aragón Fernando I», Historia 16, 233 (dossier: Comer y beber en la Edad Media), 86-90.

- (1994c), «Fuentes indirectas para el estudio del dominio sobre la tierra en Aragón durante la Edad Media: ejemplos y consideraciones», en Metodología de la investigación científica sobre fuentes aragonesas (IX Jornadas), Zaragoza, Instituto de Ciencias de la Educación de la Universidad de Zaragoza, 215-220.

- (1994d), «Introducción: Cortes generales y cortes particulares en la Corona de Aragón», en Las cortes valencianas en la época foral, Valencia, Corts Valencianes, 1994.

- (1994e), «La naturaleza en los fueros medievales hispánicos», en La imagen de la naturaleza en el arte medieval, Oviedo, Universidad de Oviedo.

— (1994f), «La expansión agraria del Occidente (ss. XI-XIII)», «Revolución mercantil y renacimiento urbano (ss. XI-XIII)» y «La maduración de la sociedad feudal (ss. XI-XIII)», en E. Mitre y otros, Manual de Historia Universal. 3. Alta Edad Media, Madrid, Historia 16, 471-498, 499-536 y 537-567. 
SARASA, E. (1995) «Imágenes de los mudéjares», en M. . I. Álvaro, G. M. Borrás y E. Sarasa (coords.) Mudéjar (Catálogo de la exposición itinerante), Zaragoza, Ibercaja, 52-63.

- (1995a), «Los sistemas alimentarios en el reino de Aragón (siglos XII-XV)», en I Col.loqui d' Historia de l'Alimentació a la Corona d'Aragó. Edat Mitjana, vol. I, Lérida, Institut d' Estudis Ilerdencs, 185-204.

- (1995b), «Los almogávares. Del caudillaje a la república militar», Historia 16, 233, 54-58.

- (1995c), «Explotación comunal y concentración dominical en el Condado de Aragón en torno al año 1000», en J. Bertrán y E. Vives (eds.), Muntanyes i Població. El passat dels Pirineus des d'una perspectiva multidisciplinària. Centre de Trobada de les Cultures Pirinenques, Andorra, Govern d' Andorra, 235-241.

- (1995d), «Una lectura histórica del Cantar del Roldán», en Homenaje a Durán Gudiol, Huesca, Instituto de Estudios Altoaragoneses, 779-790.

- (1995e), «Antecedentes medievales del marquesado de Peñafiel. Título y Estado de la Casa de Osuna», en M. García Fernández y J. J. Iglesias (coords.), Osuna entre los tiempos medievales y modernos, siglos XIII-XVIII, Sevilla, Ayuntamiento de Osuna/Universidad de Sevilla, 105-111.

- (1995f), «La Corona de Aragón en la primera mitad del siglo XIII. Feudalización, institucionalización y proyección mediterránea», Archivo hispalense, 77, (Ejemplar dedicado a: Fernando III y su época), 379-398.

- (1996a), «Alfonso V el Magnánimo, rey de Aragón y señor del Mediterráneo (1416-1458)», en Alfonso el Magnánimo. La imagen real, Zaragoza, El Justicia de Aragón, 7-14.

- (1996b), «Presentación», en E. Sarasa (ed.), Fernando II de Aragón, el rey Católico, Zaragoza, Institución Fernando el Católico, 5-7.

- (1996c), «Repercusiones político-sociales en el reino de Aragón de la intervención de la Corona en Cerdeña (siglo XIV)», en XIV Congreso di Storia della Corona d Aragona in Italia (secc. XIII-XVIII), Sassari y Alguero, vol. 3, 723-729.

- (1996d), «Fundamentos medievales del Estado Moderno», Ius Fugit, Revista interdisciplinar de estudios histórico-jurídicos, 3-4, (Ejemplar dedicado a: El Estado Moderno a uno y otro lado del Atlántico), 487-498.

- (1996e), «Las actividades económicas en una época de crisis (siglos XIV-XV)», en J. J. Carreras y otros, Historia de Aragón. II: economía y sociedad, Zaragoza, Institución Fernando el Católico, 87-99.

- (1996f), «La sociedad aragonesa en la baja Edad Media», en J. J. Carreras y otros, Historia de Aragón. II: economía y sociedad, Zaragoza, Institución Fernando el Católico, 327-343.

- (1996g) «El papa Luna y la Corona de Aragón. El compromiso de Caspe», en VI Centenario del Papa Luna 1394-1994. Jornadas de estudio, Calatayud, Centro de Estudios Bilbilitanos/Institución Fernando el Católico, 7-20. 
SARASA, E. (1996h), «Semblanza de Alfonso II, rey de Aragón y fundador de Teruel», Turia, 38, 235-254.

- (1996i), «¿San Pedro patrón de Aragón?», Serrablo, 100, 65-66.

- (1997a), «Monarquía, cortes y ciudades en la Corona de Aragón: siglo XV», en M. González (coord.), La Península Ibérica en la era de los descubrimientos: 13911492, Sevilla, Universidad de Sevilla, 611-626.

- (1997b), «Historia local, historia regional. Calatayud y comarca», en Actas del IV Encuentro de Estudios Bilbilitanos, Zaragoza, Institución Fernando el Católico, vol. 2, 107-117.

- (1997c), «Aragón y su proyección en el Mediterráneo medieval, origen de la presencia de España en Italia», en El Mediterráneo: hechos de relevancia históricomilitar y sus repercusiones en España (V Jornadas Nacionales de Historia Militar), Sevilla, Universidad de Sevilla-Junta de Andalucía, 309-328.

- (1997d), «La incidencia del patrimonio real en el tejido social aragonés durante la Baja Edad Media», en M. Sánchez, A. Furió y P. Bertrán (coords.), Col.loqui Corona, Municipis i Fiscalitat a la Baixa Edat Mitjana, Lérida, Institut d`Estudis Ilerdencs, 349-365.

- (1997e), «El reino de Aragón en la época de Jaime II (1291-1327)», Anales de la Universidad de Alicante. Historia medieval, 11 (ejemplar dedicado a: Congreso internacional Jaime II, 700 años después), 301-314.

- (1998a), «El palacio mudéjar. Introducción histórica» y «Textos cristianos medievales», en A. Beltrán (dir.), La Aljafería, Zaragoza, Zaragoza, Cortes de Aragón, vol. I, 141-154 y vol. II, 91-103.

- (1998b), «Aragón y su intervención militar en el Mediterráneo medieval», Militaria. Revista de cultura militar, 12, 31-48.

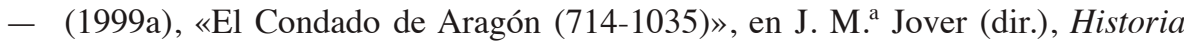
de España Menéndez Pidal. Tomo VII /2: La España cristiana de los siglos VIII al XI. Los núcleos pirenaicos (718-1035). Navarra, Aragón y Cataluña, Madrid, Espasa-Calpe, 269-362.

- (1999b), «Génesis histórica de la identidad navarra: la cronística medieval», en Mito y realidad en la historia de Navarra (Actas del IV Congreso de Historia de Navarra), Pamplona, Gobierno de Navarra, vol. 3, 219-229.

- (1999c), «Benedicto XIII y la Corona de Aragón», en IV Encuentro de Estudios Bilbilitanos, Zaragoza, Institución Fernando el Católico, 6-21.

- (1999d), «La Gobernación General en Aragón durante la Baja Edad Media», Anales de la Universidad de Alicante. Historia Medieval, 12, 9-20.

- (1999e), «La Corona de Aragón: reinos, condados y señoríos. Un análisis, una interpretación, una propuesta», en J. Valdeón (coord.), Las Españas medievales, Valladolid, Universidad de Valladolid y Fundación Duques de Soria, 27-42. 
SARASA, E. (1999f), «Juan Fernández de Heredia: consejero de reyes», en E. Sarasa y otros, Juan Fernández de Heredia, IV Centenario (Jornada Conmemorativa del VI Centenario, Munébrega, 1996), Zaragoza, Centro de Estudios Bilbilitanos e Institución Fernando el Católico, 9-20.

- (1999g), «Caminar en la Edad Media», en M. a Á Magallón (coord.), Caminos y comunicaciones en Aragón, Zaragoza, Institución Fernando el Católico, 95-100.

- (1999h), «Aragón y los reinos peninsulares en la época de Santa Isabel», en Imagen de la Reina Santa. Santa Isabel, infanta de Aragón y reina de Portugal. Zaragoza, Diputación de Zaragoza, vol. II, 41-49.

- (1999i), «La expansión territorial y los mudéjares», en G. Fatás y otros, Aragón, reino y corona, Zaragoza, Gobierno de Aragón e Ibercaja, 61-68.

- (2000a), «La supresión de la Orden del Temple en Aragón. Proceso y consecuencias», en R. Izquierdo y F. Ruiz (coords.), Las órdenes militares en la Península Ibérica. Vol. I: Edad Media, Cuenca, Universidad de Castilla-La Mancha, 379-401.

- (2000b), «Política y fueros. Repoblación y organización espacial turolense», en J.M. Latorre (coord.), Los fueros de Teruel y Albarracín, Teruel, Instituto de Estudios Turolenses, 31-41.

- (2000c), «Un rey del año mil: Sancho Garcés III de Navarra. Sancho el Mayor (992? 1004-1035)», en J. A. García de Cortázar (coord.), Los protagonistas del año mil. (Actas XIIl Seminario sobre Historia del monacato), Aguilar de Campoo (Palencia). Fundación Santa María la Real, 117-132.

- (2000d), «Martín el Humano, Aragón y Tobed», en El icono de la Virgen de Tobed. VI Centenario (1400-2000), Madrid, Centro de Estudios del Santo Sepulcro, 7-14.

- (2000e), «El libro-registro del monedaje del año 1349. Una fuente para el estudio de la ciudad de Calatayud a mediados del siglo XIV», en V Encuentro de Estudios Bilbilitanos, Calatayud, Centro de Estudios Bilbilitanos, 139-173.

- (2001a), «El Justicia de Aragón en los cronistas», en Primer encuentro de estudios sobre el Justicia de Aragón, Zaragoza. El Justicia de Aragón, 11-15.

- (2001b), La Corona de Aragón en la Edad Media, Zaragoza, Caja de Ahorros de la Inmaculada.

- (2001c), «La sociedad medieval aragonesa», en Ag. Ubieto (dir.), II Jornadas de estudios sobre Aragón en el umbral del siglo XXI, Zaragoza, Instituto de Ciencias de la Educación, 189-198.

- (2001d), «Prólogo», en M. Pallarés, La Caja de Valderrobres o Peña de Aznar la Gaya. Noticias históricas de Valderrobres, Fuentespalda, Mezquín, Beceite y Torre del Compte, Alcañiz, Centro de Estudios Bajoaragoneses. Edición facsimilar.

- (2002a), «La construcción de una memoria de identidad. El género historiográfico en la Edad Media: de la europea a la hispana», en J. I. de la Iglesia (coord.), Los espacios de poder en la España Medieval. XII Semana de Estudios Medievales, Nájera, Instituto de Estudios Riojanos, 409-424. 
SARASA, E. (2002b), «Los mudéjares: pervivencias del mundo islámico en Aragón», Trébede, Mensual Aragonés de Análisis, Opinión y Cultura, 62, 43-48.

- (2002c), «Los mudéjares: pervivencia del mundo islámico en Aragón: veinticinco años de estudios», Revista d'historia medieval, 12 (ejemplar dedicado a: Los mudéjares valencianos y peninsulares), 79-90.

- (2002d), «Las Universidades de Huesca y Perpiñán», en J. Busqueta y J. Pemán (coords.), Les universitats de la Corona d'Aragó, ahir i avui. Estudis històrics, Barcelona, Universitat de Lleida-Pòrtic, 117-123.

- (2002e), «La última crisis del condado de Urgel», en El comtat d'Urgell a la Península Ibèrica, Lleida, Universitat de Lleida e Institut d'Estudis Ilerdencs, 33-43.

- (2002f), «El Archivo de la Corona de Aragón. Memoria histórica del pasado y permanente actualidad», Turia, 62, 257-265.

- (2002g), «Las Cortes en la Corona de Aragón» y «El nacimiento de la Corona de Aragón», en F. García de Cortázar (dir.), La Historia en su lugar: nueva historia de España. Vol. 4. De la crisis medieval a los reyes católicos, siglos XIV-XV, Barcelona, Planeta, 19-30 y 35-38.

- (2002h), «Las Cortes del Reino de Aragón (siglos XIII-XVIII)», en Aragón, de reino a comunidad. Diez siglos de encuentros. Zaragoza, Cortes de Aragón, 43-50.

- (2002i), «La ciudad de Teruel en la baja Edad Media (siglos XII-XV», en F. J. Sáenz Guallar (dir.), Historia ilustrada de la provincia de Teruel, Teruel, Diario de Teruel e Instituto de Estudios Turolenses, 209-224.

- (2003), «Los mudéjares aragoneses en la Edad Media», en M. ${ }^{a}$ I. Álvaro, G. Borrás y E. Sarasa, Los mudéjares en Aragón, Zaragoza, Caja de Ahorros Inmaculada, 13-69.

- (2004a), Libro-registro del merino de Zaragoza de 1387 (Transcripción, edición y estudio introductorio), Zaragoza, Instituto de Estudios Islámicos y del Oriente próximo (CSIC)-Cortes de Aragón-Universidad de Zaragoza, 2004.

- (2004b), «El Justicia de Aragón y las Cortes en la Edad Media», en Cuarto encuentro de estudios sobre el Justicia de Aragón, Zaragoza, El Justicia de Aragón, 187-194.

- (2004c), «La bataille. Batailla et destin historique», Heresis, Revue d'Histoire des Dissidences Medievales, 41, 37-41. (Dossier: «Muret, Muret, Morne plaine! Reflexions sur El jueves de Muret de Martín Alvira Cabré: cinque questions posées à l'auteur»).

- (2004d), «Hermandades y cofradías. Orígenes históricos y compromiso social», en VI Encuentro de hermandades y cofradías de Aragón. Junta de Cofradías y Hermandades de Semana Santa de la ciudad de Teruel, Teruel, 56-63.

- (2005), «Introducción», en G. Redondo y E. Sarasa (coords.), Colección de Cortes de los antiguos reinos de España. Por la Real Academia de la Historia, edición facsimilar de la de 1855, Zaragoza, Cortes de Aragón, 15-26. 
SARASA, E. (2005a), «Los aragoneses en la proyección mediterránea de la Corona: sobre Cerdeña en 1356», en R. Narbona (coord.), La Mediterrània de la Corona d'Aragó, segles XIII-XVI \& VII Centenari de la Sentència Arbitral de Torrellas, 1304-2004 (XVIII Congrés d’Historia de la Corona d’Aragó, Valencia, 2004), Valencia, Universitat de Valéncia, vol. 1, 201-208.

- (2005b), «La Concordia de Alcañiz», en J. I. Micolau y T. Thomson (coords.), Comarca del Bajo Aragón, Zaragoza, Gobierno de Aragón, 89-91. (Colección Territorio 18).

- (2005c), «Notas sobre la comarca de los Monegros en la Edad Media», en G. Gavín (coord.), Comarca de Los Monegros, Zaragoza, Gobierno de Aragón, 101108. (Colección Territorio 16).

- (2005d), «Domingo Ram. Un alcañizano ilustre», Boletín del Centro de Estudios Bajoaragoneses, 9-10, 61-73.

- (2006a), «Las Órdenes Militares en las crónicas de la Corona de Aragón», en Las Órdenes Militares en la Comunidad Valenciana (Gandía 2004), Valencia, Real Academia de Cultura Valenciana. Aula de Humanidades, 129-143.

- (2006b), «El tiempo histórico, político y cultural de San Diego de Alcalá», Anales Complutenses, 18, 31-44.

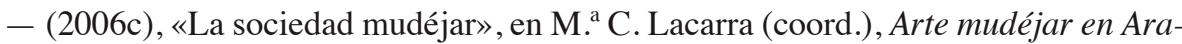
gón, León, Castilla, Extremadura y Andalucía, Zaragoza, Institución Fernando el Católico, 7-29.

- (2006d), «La historiografía sobre la institución del Justicia de Aragón en la Edad Media», en Sexto Encuentro de Estudios sobre el Justicia de Aragón. Instrumentos para el conocimiento de los orígenes y desarrollo de una institución clave en la Edad Media, Zaragoza, Justicia de Aragón y Universidad de Zaragoza, 53-63.

- (2006e), «Estudio preliminar», en Libro rojo de los privilegios de Ejea, edición facsimilar, Zaragoza, Diputación de Zaragoza y Ayuntamiento de Ejea.

- (2006f), «Tenencias, alcaidías y caballerías en Aragón durante la Edad Media», en J. V. Cabezuelo (coord.), Alcaidías y fortalezas en la España Medieval, Alicante, Universidad de Alicante, 137-154. (Colección Universitas Philologica et Historica 10/1).

- (2006g), «Biografías imprescindibles: Fernando el Católico, príncipe del Renacimiento», Clío. Revista de Historia, 61, 78-89.

- (2006h), «Fernando II de Aragón, príncipe del Renacimiento: panorama general de un reinado», en R. Centellas (coord.), Ferdinandus, Rex Hispaniarum, Zaragoza, Cortes de Aragón y Diputación Provincial de Zaragoza, 3-16.

- (2006i), «España en las crónicas de la Corona de Aragón en la Edad Media (siglos XII-XV)», Norba, Revista de Historia, 19, 95-103.

- (2007a), «Teruel Medieval: el concejo, el territorio y la frontera», en D. FernándezGaliano (coord.) Tierras de frontera (Catálogo de la exposición Teruel y Albarracín), Zaragoza, Gobierno de Aragón e Ibercaja, 155-163. 
SARASA, E. (2007b), «La sociedad cristiana turolense en la Edad Media», en Tiempo de derecho foral en el sur aragonés: los fueros de Teruel y Albarracín. Vol 1. Estudios, Zaragoza, El Justicia de Aragón e Ibercaja, 131-141.

- (2007c), «El medievalista en el franquismo», Revista de historia Jerónimo Zurita, 82, 27-38.

- (2008a), «El Compromiso de Caspe (1412). Una lección de Historia» y «La interculturalidad mudéjar», en R. Sevilla y J. Tudela (eds.), Aragón. Interculturalidad y compromiso, Tubinga, Länderseminare, Horlemann y Centro de Comunicación Científica con Iberoamérica, 22-29 y 149-165.

- (2008b), «Una introducción al libro de Julián Ribera, 'Orígenes del Justicia de Aragón’, de 1897», en J. Ribera, Orígenes del Justicia de Aragón, edición facsimilar, Zaragoza, El Justicia de Aragón, 13-37.

- (2008c), «La economía hidráulica en el valle medio del Ebro: de la explotación islámica a la cristiana», en M. I del Val y O. Villanueva (coords.) Musulmanes y cristianos frente al agua en las ciudades medievales, Santander, Universidad de Cantabria, 155-171.

- (2008d), «Fueros y ordenamientos jurídicos locales en España: un proyecto integrador», Arbor: Ciencia, pensamiento y cultura, Extra 1 (Ejemplar dedicado a: Los estudios locales en España), 45-50.

- (2009a),«Recesión económica, crisis estructural y antagonismo social en Aragón a finales del siglo XIII y comienzos del XIV», en M. ${ }^{a}$ I. del Val (coord.), Castilla y el mundo feudal (Homenaje al profesor Julio Valdeón), Valladolid, Junta de Castilla y León-Universidad de Valladolid, vol. III, 41-52.

- (2009b) «El justicia de Aragón en la Edad Media. Génesis y primer desarrollo», en Octavo encuentro de estudios sobre el Justicia de Aragón, Zaragoza, El Justicia de Aragón, 19-28.

- (2010a), «De mudéjares a moriscos», Serie histórica, 31, 365-378.

- (2010b), «La implantación de la Orden del Temple en Aragón. Precedentes, ambiente y consecuencias en el siglo XII», en Actes de les Jornades Internacionals d'Estudi sobre els orígens i l'expansió de l'orde del Temple a la Corona d'Aragó (1120-1200), Tarragona, Diputació de Tarragona, 273-282.

- (2011), «La gestación de las Cortes de Aragón en el reinado de Jaime I (12131276)», en M. ${ }^{a}$ T. Ferrer (ed.), Jaume I. Commemoració del VIII centenari del naixement de Jaume I, Barcelona, Institut d'Estudis Catalans, vol. I, 359-366.

- (2012a), «El Compromiso de Caspe en su sexto centenario. Una revisión bibliográfica», Índice Histórico Español, 125, 195-216.

- (2012b), «Sin rey no hay Cortes. Los parlamentos del Interregno (1410-1412) en la Corona de Aragón», en D. Repeto (coord.), Las Cortes de Cádiz y la historia parlamentaria, Cádiz, Universidad de Cádiz, 699-709. 
SARASA, E. (2012c), «La hora de la diplomacia. Aragón sube al estrado», La aventura de la Historia, 164, 68-73.

- (2012d), «Aragón en la Concordia de Alcañiz y el Compromiso de Caspe de 1412», Turia , 103, 365-378.

- (2013a), «El Compromiso de Caspe: el hecho histórico», en El Compromiso de Caspe (1412). Cambios dinásticos y constitucionalismo (XIX Congreso de la Corona de Aragón), Zaragoza, Gobierno de Aragón, 117-127.

- (2013b), «Aragón y el Compromiso de Caspe», Rolde. Revista de Cultura Aragonesa, 143-144, 60-67.

- (2013c), «La mesa del rey: Fernando I de Aragón (1412-1416)», en M. García Guatas, E. Piedrafita y J. Barbacil (coords.), La alimentación en la Corona de Aragón (siglos XIV-XV), Zaragoza, Institución Fernando el Católico, 1-20.

- (2013d), «'Los Anales de la Corona de Aragón’ de Jerónimo Zurita», Revista de Historia Jerónimo Zurita, 88, 61-80.

- (2014a), «Urraca Alfonsi (1081-1126), esposa de Alfonso I el Batallador», en J. Pavón (coord.), Reinas de Navarra, Madrid, Gobierno de Navarra/Silex, 241-265.

- (2014b), «De efemérides, aniversarios y estancias reales. Fernando I de Aragón (1412-1416) en Zaragoza», en A. Duplá, M. ${ }^{a}$ V. Escribano, L. Sancho y M. . A. Villacampa (eds.), Miscelánea de Estudios en homenaje a Guillermo Fatás Cabeza, Zaragoza, Institución Fernando el Católico, 635-643.

- (2015), «Las cortes de Aragón en el reinado de Martín el Humano», en M. a T. Ferrer (ed.), Martí l'Humà: el darrer rei de la dinastia de Barcelona (1396-1410): l'Interregne i el Compromís de Casp, Barcelona, Institut d'Estudis Catalans, 199206.

— «El setge de Balaguer de 1413», en O rei o res. 600 anys del fi del Comtat d'Urgell, Museu de la Noguera [en prensa].

— «Obras de mudéjares en la Aljafería entre 1391-1392, según los registros del merino de Zaragoza», XIII Simposium internacional de mudejarismo [en prensa]

SARASA. E. (coord.) (1994), Sancho Ramírez, rey de Aragón y su tiempo (10641094), Huesca, Instituto de Estudios Altoaragoneses.

- (1999), Libro de los Privilegios de Fraga y sus aldeas, Zaragoza, Cortes de Aragón.

- (2009), La sociedad en Aragón y Cataluña en el reinado de Jaime I (1213-1276), Institución Fernando el Católico, Zaragoza.

- (2014), Monarquía, crónicas, archivos y cancillerías en los reinos hispanocristianos: siglos XIII-XV, Zaragoza, Institución Fernando el Católico.

SARASA, E., COLÁS, G. y FORCADELL, C. (1981), «La Historia Agraria», en III Jornadas sobre el estado actual de los estudios de Aragón, Zaragoza, Instituto de Ciencias de la Educación de la Universidad de Zaragoza, vol. 2, 791-854.

- y ORCÁSTEGUI, C. (1985), «Aragón en la Baja Edad Media», en Historia de Aragón, Zaragoza, Guara, vol. VI, 9-148. 
SARASA. E. y otros (1987), Les Marches Méridionales du Royaume des Francs aux alentours de l'an Mil. Inventaire Typologique des Sources Documentaires (Colloque Hugues Capet, 987-1987, la France de l'an mil), Nancy (France), Presses Universitaires de Nancy.

- y otros (1989), Cortes y parlamentos de la Corona de Aragón, Zaragoza-Barcelona-Madrid, Editorial Aragó.

SARASA, E., PALACIOS, E., PÉREZ, P., SESÉ, A., TAUSIET, M. a y YUS, J. E. (1988), «Balance crítico y perspectivas de una década sobre la Historia de Aragón en la Edad Media (1975-1985)», Studia historica, 6, 57-93.

SARASA, E. y SERRANO, E. (1993), «La Cátedra Zurita. La Sección de Historia y Ciencias Historiográficas», en Institución Fernando el Católico, Cincuenta años al servicio de la cultura en Aragón (1943-1993), Zaragoza, Institución Fernando el Católico, 197-206.

SARASA, E. y SERRANO, E. (coords.) (1999), Historiadores de la España medieval y moderna. Revista de Historia Jerónimo Zurita, 73 (1998), Zaragoza, Institución Fernando el Católico.

SARASA, E. y SERRANO, E. (eds.) (2010), Estudios sobre señorío y feudalismo. Homenaje a Julio Valdeón, Zaragoza, Institución Fernando el Católico.

SERRANO, E., FERRER BENIMELI, J. A. y SARASA, E. (coords.) (2000), El conde de Aranda y su tiempo. Congreso Internacional (1998), Zaragoza, Institución Fernando el Católico.

SERRANO, E. y SARASA, E. (coords.) (1993), Señorío y feudalismo en la Península Ibérica (siglos XII-XIX), Zaragoza, Institución Fernando el Católico, 4 vols.

- y SARASA, E. (coords.) (1997f), La Corona de Aragón y el Mediterráneo, siglos $X V$-XVI, Zaragoza, Institución Fernando el Católico.

SESMA, J. Á. y SARASA, E. (1976a), Cortes del reino de Aragón (1357-1451). Extractos y fragmentos de procesos desaparecidos. Valencia, Anubar.

- y SARASA, E. (1976b), «Los poderes de las cortes aragonesas», Historia 16, 5, 79-82.

- y SARASA, E. (1978), «El comercio de la lana por el Ebro hacia el Mediterráneo. El puerto fluvial de Escatrón a mediados del siglo XV», en II Congreso Internacional de estudios sobre las culturas de Mediterráneo Occidental, Barcelona, Universidad Autónoma de Barcelona, Instituto Universitario de Estudios Medievales, 399-409.

\section{Otras referencias citadas}

ARTOLA, M. (dir.), (1988-1993), Enciclopedia de Historia de España, Madrid, Alianza. 7 vols. 
CHEJNE, Anwar G. (1980), Historia de España musulmana, Madrid, Cátedra.

FATÁS CABEZA, G. (dir.) (1990- ), Gran Enciclopedia de España, Zaragoza, Enciclopedia de España.

FERNÁNDEZ CLEMENTE, E. (dir.), (1980-1983), Gran Enciclopedia Aragonesa. Zaragoza, Unali. 12 vols.

LACARRA, J. M. (1972), Aragón en el pasado, Madrid, Espasa-Calpe.

LALINDE, J. (1976), «Contabilidad e intervención en el Reino aragonés», en Itinerario histórico de la intervención general de la Administración del Estado, Madrid, Instituto de Estudios Fiscales, 39-55.

MASIÁ DE ROS, A. (1950), «El Maestre Racional en la Corona de Aragón. Una Pragmática de Juan II sobre dicho cargo», Hispania, X, 25-60.

NARBONA, R., MUÑOZ, R. y CRUSELLES, E. (1988), «Las instituciones», en M. Cerdá (dir.), Historia del pueblo valenciano, Valencia, Levante. 